This is a post-peer-review, pre-copyedit version of an article published in Journal of Business and Psychology. The final authenticated version is available online at:

http://dx.doi.org/10.1007/s10869-016-9455-8 


\title{
The usefulness of tenacity in spurring problem-focused voice: The moderating roles of workplace adversity
}

\begin{abstract}
Purpose-Drawing from conservation of resources (COR) theory and affective events theory (AET), this article examines the hitherto unexplored relationship between employees' tenacity levels and problem-focused voice behavior, as well as how this relationship may be augmented when employees encounter adversity in relationships with peers or in the organizational climate in general.

Design/methodology/approach-The study draws on quantitative data collected through a survey administered to employees and their supervisors in a large manufacturing organization.

Findings-Tenacity increases the likelihood of speaking up about problem areas, and this relationship is strongest when peer relationships are characterized by low levels of goal congruence and trust (relational adversity) or when the organization does not support change (organizational adversity). The augmenting effect of organizational adversity on the usefulness of tenacity is particularly salient when it combines with high relational adversity, which underscores the critical role of tenacity for spurring problem-focused voice behavior when employees negatively appraise different facets of their work environment simultaneously.

Implications - The results inform organizations that the allocation of personal energy to reporting organizational problems is perceived as particularly useful by employees when they encounter significant adversity in their work environments.

Originality/value - This study extends research on voice behavior by providing a better understanding of the likelihood that employees speak up about problem areas, according to their levels of tenacity, and explicating when this influence of tenacity tends to be more prominent.

Keywords—voice behavior; tenacity; workplace adversity; conservation of resources theory; affective events theory
\end{abstract}




\section{Introduction}

Employees can contribute to organizational effectiveness through voice behaviors, such that they speak up about how the current organizational situation can be improved (Van Dyne, Ang, \& Botero, 2003; Venkataramani \& Tangirala, 2010). Voice behaviors are useful for both

the organization and the employees themselves, in that they may fuel employees' satisfaction and motivation (Greenberger \& Strasser, 1986; Parker, 1993), contribute to their career development (Siebert, Kraimer, \& Crant, 2001), and enhance their ability to meet their job requirements (Fuller, Barnett, Hester, Relyea, \& Frey, 2007; Van Dyne \& LePine, 1998). For example, with problem-focused or prohibitive voice, the employee reports on specific problem areas or failures in the organization (Liang, Farh, \& Farh, 2012), which in turn implies the need to find solutions to current organizational issues. Such voice behaviors have clear benefits, but speaking up about specific problems also may be perceived by others as disruptive or upsetting (Milliken, Morrison, \& Hewlin, 2003; Van Dyne, Cummings, \& McLean Parks, 1995), especially if the changes recommended through this voice behavior threaten the privileges that other organizational members currently enjoy (LePine \& Van Dyne, 1998).

To encourage problem-focused voice behaviors and ensure that they can overcome the potential barriers to change, a key catalyst may be the tenacity levels that employees exhibit. Tenacity is a personal trait that reflects employees' sustained allocation of goal-directed energy to work tasks (Baum \& Locke, 2004). The perseverance and enhanced energy levels that characterize tenacious people can lead to several positive outcomes, such as effective leadership (Bass \& Stogdill, 1990; House \& Shamir, 1993), the achievement of growth-oriented goals (Baum \& Locke, 2004), and enhanced sales performance (Avila \& Fern, 1986). To the best of our knowledge though, no studies address how tenacity might influence the likelihood that 
employees engage in energy-consuming, problem-focused voice behaviors. This omission has important practical relevance, because it prevents organizations from understanding how the tenacity of their employees might produce the resolve necessary to enable them to pinpoint problem areas and withstand sustained resistance to or criticism of their voice behaviors (Van Dyne et al., 2003). Furthermore, tenacity has some overlap with the personality dimension of conscientiousness, which stimulates voice behaviors (Crant, Kim, \& Wang, 2011; LePine \& Van Dyne, 2001 or 1998), though it differs in that it excludes the short-term dependability aspect of conscientiousness (Crant et al., 2011) and focuses instead on employees' persistent, long-term efforts to undertake challenging work activities (Baum \& Locke, 2004). ${ }^{1}$

Accordingly, this study seeks to identify both how and when employees' tenacity enhances their propensity to engage in problem-focused voice behaviors. To anchor our arguments, we draw from two core theories: conservation of resources (COR) theory, which uses anticipated resource gains or losses to explain work behaviors (Hobfoll, 1989, 2001), and affective events theory (AET), which acknowledges the influence of the negative feelings that employees experience when they appraise their work environment as unfavorable (Weiss \& Beal, 2005). According to COR theory, employees engage in positive work behaviors, such as voice, when they can leverage their personal resources to obtain additional resources through these behaviors (Boon \& Kalshoven, 2014; Hobfoll, 2001). Tenacity is one such personal resource, in that it reflects the discretionary energy employees can draw from to achieve

\footnotetext{
${ }^{1}$ Conscientious people focus on controlling the immediate, short-term outcomes of their actions; perseverance and the long-term focus of tenacity thus are qualities that conscientious people may or may not have (Duckworth, Peterson, Mathews, \& Kelly, 2007). Tenacity is closer to the concept of grit, which refers to people's perseverance and passion for long-term goals (Duckworth et al., 2007). In describing the effect of grit on academic performance, Duckworth et al. (2007) highlight the relevance of Baum and Locke's (2003) tenacity scale for conceptualizing grit; they chose to develop a new measure so that the concept was directly applicable to the adolescents they studied. However, this previous research shows that grit has incremental predictive validity, beyond conscientiousness, for explaining outcomes such as work engagement (Suzuki, Tamesue, Asahi, \& Ishikawa, 2015), educational achievement (Duckworth \& Quinn, 2009), and psychical exercise (Duckworth et al., 2007).
} 
valuable, long-term work goals (Baum \& Locke, 2004). In COR theory, the achievement of resource or performance gains through positive work behaviors is particularly useful when employees experience adverse work conditions that seem likely to generate future resource losses (Hobfoll \& Shirom, 2000). Similarly, AET suggests that the allocation of personal resources to performance-enhancing work behaviors will have greater anticipated value when employees appraise their work environment more negatively and fear that it undermines their ability to meet their job requirements (Weiss \& Cropanzano, 1996). With this theoretical foundation, we investigate how two aspects of workplace adversity — a relational aspect marked by low goal congruence and trust in peer interactions (Leana \& van Buren, 1999) and an organizational aspect manifested in an organizational climate that opposes change (Scott \& Bruce, 1994) — might invigorate the positive effect of employees' tenacity on problem-focused voice behavior. The positive relationship between tenacity and problem-focused voice seemingly should be stronger to the extent that employees believe their colleagues have different goals or cannot be trusted and when the organizational climate is rigid and not open to new ideas.

In turn, we contribute to extant voice research by investigating an unexplored driver of employee voice (tenacity) and explicating when tenacity is most likely to spur voice. According to the existing exit, voice, loyalty, and neglect framework (Hirschman, 1970; Rusbult, Farrell, Rogers, \& Mainus, 1988), voice is just one of four possible behavioral reactions to difficult work conditions. Exit implies leaving the organization, by searching for a different job or quitting; loyalty means passive waiting and hoping for improvement; and neglect captures reduced interest or effort. Compared with loyalty and neglect, voice is an active instead of passive response, and compared with exit and neglect, voice is a constructive instead of destructive response ( $\mathrm{Si} \& \mathrm{Li}, 2012)$. The active, constructive nature of voice makes it a particularly 
interesting type of behavior, for which high tenacity levels might be instrumental. Furthermore, previous research acknowledges that personal characteristics, such as personality traits (Crant et al., 2011) or duty and achievement orientations (Tangirala, Kamdar, Venkataramani, \& Parke, 2013), influence employee voice in general, but no studies investigate the role of employees' tendency to allocate sustained energy to work tasks (tenacity) in activating problem-focused voice behaviors, irrespective of the challenges they might invoke. This omission is significant in light of the strong resistance that reports of organizational malfunctioning likely generate among other organizational members (LePine \& Van Dyne, 1998; Milliken et al., 2003). Our focus on problem-focused voice thus aligns with calls to devote attention to the type of information conveyed through voice efforts (Morrison, 2011) — in this case, information that brings specific organizational problems into the open instead of focusing on organizational improvements in general (Liang et al., 2012).

We further postulate that the salience of this positive effect of tenacity for stimulating problem-focused voice behavior is particularly high when employees confront significant adversity in their work environment, whether due to poor peer relations (Leana \& van Buren, 1999) or a rigid organizational climate (Scott \& Bruce, 1994). These forms of adversity are manifested in three moderators - goal congruence, trust, and organizational support for change, or their lack - that together provide a parsimonious, comprehensive view of how employees' negative appraisal of their work environment may increase their perceptions of the usefulness of leveraging their tenacity to engage in problem-focused voice (Weiss \& Cropanzano, 1996). The glue that binds the three moderators is that any deficiency in one of them is likely to instill significant uncertainty in employees, in terms of their ability to perform their job tasks successfully (De Clercq, Dimov, \& Thongpapanl, 2013; Yuan \& Woodman, 2010). We also 
extend this view to consider how the simultaneous interplay of the different sources of workplace adversity, such as relational and organizational adversity, might invigorate the value of tenacity_an approach that has received little attention in previous COR (Hobfoll, 2011; Wright \& Hobfoll, 2004) or AET (Weiss \& Cropanzano, 1996) applications. That is, we postulate that the invigorating effect of organizational adversity (limited organizational support for change) on the relationship between tenacity and problem-focused voice is particularly strong when employees cannot rely on supportive peer relationships (marked by goal congruence and trust).

Finally, by investigating the usefulness of tenacity for spurring problem-focused voice behaviors in unfavorable work situations, we extend previous research that has focused on the direct effects of workplace adversity on positive work behaviors — such as perceptions of unfairness that increase voice due to the desire to express concerns about unfairness (Goldberg,

Clark, \& Henley, 2011) or to restore equity following injustice (Avery \& Quinones, 2002)—and on negative work behaviors, as reflected in findings of a positive relationship between perceptions of injustice and counterproductive work behaviors (Jones, 2009). With our approach, organizations can identify the circumstances in which employees are most likely to apply their personal energy to activities that can resolve organizational malfunctions (Morrison, 2011). The proposed invigorating effect of workplace adversity on the relationship of tenacity with problemfocused voice thus offers the insight that anticipated solutions to identified problem areas, achieved through problem-focused voice, can help tenacious employees address the negative feelings caused by adversity (Hobfoll \& Shirom, 2000; Weiss \& Beal, 2005).

\section{Theoretical Background and Hypotheses}

Problem-focused voice behaviors can benefit the organization and the idea proponents. For example, bringing negative situations into the open can stimulate organizational learning 
(Argyris \& Schon, 1978) and change (Morrison \& Milliken, 2000). For idea proponents, identifying and speaking up about problem areas can add to their work motivation (Parker, 1993), increase their career progress (Seibert et al., 2001), and contribute to their ability to meet performance requirements (Van Dyne \& LePine, 1998). Despite these positive outcomes, such voice behaviors also are challenging, so idea proponents may require sustained energy to engage in them (Liang et al., 2012). For example, organizational leaders may disagree about whether the issues raised present actual problems or whether the voice is well intentioned (Maynes \& Podsakoff, 2014), and they may discard employees' input out of fear of a loss of power when the problems are tied directly to them (Morrison, 2011; Van Dyne et al., 1995). Speaking up about problem areas also can damage idea proponents' own standing in the organization, to the extent that their activities violate current organizational rules and norms (Milliken et al., 2003).

Because energy is needed to address these challenges, it is important to understand how employees' personal energy reservoirs may stimulate their propensity to speak out about problems (Hobfoll, 1989). Previous research on the role of individual factors in spurring voice has examined the Big Five personality traits, indicating positive effects of conscientiousness, extraversion, and agreeableness but negative effects of neuroticism (LePine \& Van Dyne, 2001), as well as traits such as duty and achievement orientation (Tangirala et al., 2013). We focus instead on employees' tenacity or "sustained goal-directed action and energy even when faced with obstacles" (Baum \& Locke, 2004, p. 588), because of its likely benefits for prompting such behaviors. In leadership research, tenacity spurs successful leaders (Bass \& Stogdill, 1990; House \& Shamir, 1993), and in entrepreneurship literature, Baum and Laucke (2004) show that higher tenacity leads to greater venture growth, by stimulating entrepreneurs' new resource skills, self-efficacy, and vision communication. Tenacity also reduces investors' perceptions of 
the risk that entrepreneurs will not use their funds effectively (Allison, McKenny, \& Short, 2013). Shifting these findings to a different realm, we predict that tenacity might have a critical influence on the likelihood that employees voice their opinions about organizational problems too.

Moreover, we postulate that the gains that tenacious employees expect from their problem-focused voice behaviors should be particularly strong when they experience significant workplace adversity in undertaking their job activities. This invigorating effect of workplace adversity on the tenacity-problem-focused voice relationship echoes the COR theory argument that resource or performance gains, accumulated through positive work behaviors, are particularly useful when those gains help protect employees against the threat of resource loss due to adverse work conditions (Hobfoll, 1989; Hobfoll \& Shirom, 2000). Similarly, according to affective events theory (AET), the allocation of personal energy to performance-enhancing work behaviors, such as voice, can be instrumental for countering negative feelings that employees experience through their exposure to unfavorable work conditions (Weiss \& Cropanzano, 1996). Thus AET points to various negative emotions resulting from adverse work conditions, such as frustration, anger, or guilt (Weiss, Suckow, \& Cropanzano, 1999); we focus on the fear they may generate in employees, associated with the difficulty of achieving adequate job performance.

In turn, we consider that workplace adversity may stem from two main sources: relational and organizational. First, relational adversity is the extent to which employees cannot draw from supportive relationships with peers to meet their performance requirements. We consider both cognitive and affective aspects (Leana \& van Buren, 1999). A lack of goal congruence among employees reflects the extent to which they have different goals or ideas about their 
organization's future (Nahapiet \& Ghoshal, 1998). In the presence of low goal congruence, employees focus on their own priorities, with little incentive to cooperate or share their knowledge bases with one another (Pinto, Pinto, \& Prescott, 1993; Song \& Song, 2010). The affective component instead pertains to a lack of trust among employees (Nahapiet \& Ghoshal, 1998). If peer relationships are characterized by low levels of trust, employees believe their colleagues will not keep their promises and would take advantage of them if doing so met their own interests (Rousseau, Sitkin, Burt, \& Camerer, 1998). Second, organizational adversity is the extent to which employees believe organizational decision making is rigid and not open to change. It may create negative feelings in employees, because it hampers their flexibility to meet their job requirements and tends to be perceived as limiting their personal development or career prospects (Scott \& Bruce, 1994; Yuan \& Woodman, 2010).

Our theoretical framework and its underlying hypotheses are in Figure 1. The baseline relationship pertains to the positive link between employees' tenacity and problem-focused voice behavior. We posit that this link also is augmented by the three sources of adversity: limited goal congruence or trust in peer relationships and limited organizational support for change.

[Insert Figure 1 about here]

\section{Hypotheses}

\section{Tenacity and Problem-Focused Voice}

We predict a positive relationship between employees' tenacity levels and their propensity to speak up about problem areas. Tenacity should increase employees' propensity to speak up about organizational problems, because they expect their allocation of personal energy to behaviors that lead to appropriate solutions to generate performance gains, in the form of an enhanced ability to meet their job requirements (Baum \& Locke, 2004; Hobfoll, 2001). 
Moreover, reporting problem areas requires significant efforts from employees (Morrison, 2011), which can be facilitated by greater tenacity, because this personal resource increases the ability to allocate sustained personal energy to challenging work tasks (Baum \& Locke, 2004). In particular, voice behaviors prompt organizational changes, particularly if they entail corrections of organizational failures, so they may provoke resistance from other organizational members who feel threatened by the changes (Liang et al., 2012; Van Dyne et al., 2003). In turn, employees' tenacity should prevent them from stopping their voice behaviors, even if they anticipate that this identification of problem areas might be met with skepticism (Baum \& Locke, 2004). Thus, employees with high tenacity likely persevere and speak up, despite resistance.

Conversely, employees with low tenacity levels may not possess the energy needed to undertake the challenging task of speaking up about problem situations (Baum \& Locke, 2004). They are less able to cope with the anticipated negative reactions to their reports of problem areas, which undermines their motivation to voice their opinions (Liang et al., 2012; Van Dyne et al., 1995). They allocate their energy to easier activities instead of investing significant time to address the difficult, negative situations (Milliken et al., 2003; Quinn, Spreitzer, \& Lam, 2012). In short, with low tenacity, employees may not have the necessary energy or motivation to speak up about problem areas and likely fear the severe skepticism with which their opinions might be received.

Hypothesis 1: There is a positive relationship between employees' tenacity and problemfocused voice.

\section{Moderating Role of Relational Adversity}

The anticipated usefulness of tenacity for spurring problem-focused voice behaviors may depend on the adversity that employees experience in their relationships with peers. Such relational adversity can be cognitive, such as when employees have different goals, or affective, 
as when employees believe their colleagues cannot be trusted (Leana \& van Buren, 1999). These two conditions increase the threat of future resource losses and the fear that employees cannot meet their job requirements (Hobfoll, 1989), because they diminish high-quality knowledge sharing among organizational peers and the opportunities for employees to draw from their peers' expertise to enhance their own performance (De Clercq et al., 2013; Wells \& Kipnis, 2001). Yet tenacious employees should be more strongly motivated to apply their personal energy to speak up about problem areas, in that the anticipated solutions (i.e., performance gains) might compensate for the knowledge deficiencies associated with poor interpersonal relationships (Hobfoll \& Shirom, 2000). Thus, following the logic of COR theory, we predict that the usefulness of tenacity for speaking up about problem areas increases to the extent that relational adversity, a critical source of resource loss, is high.

The positive interaction between tenacity and relational adversity in predicting problemfocused voice is also consistent with affective events theory (Weiss \& Cropanzano, 1996), in that the allocation of personal energy to speaking up about problem areas may appear helpful for improving the quality of poor peer relationships. For example, the concern that colleagues may have conflicting ideas about where the organization is heading strategically or that others might take undue credit for offered contributions may stimulate tenacious employees to engage their peers directly to find a collective solution that addresses these unfavorable situations (Baum \& Locke, 2004; Morrison \& Milliken, 2000). The more negatively employees appraise their relationships with organizational peers, due to either incongruent goals or limited trust, the more valuable it becomes to apply significant energy to share concerns about problem areas, to find adequate solutions to this relational adversity (Weiss \& Cropanzano, 1996). Conversely, in the absence of relational adversity, tenacious employees perceive less need to apply their energy in 
engaging colleagues to find solutions to adverse work relationships, so the perceived value of

leveraging significant personal energy to communicate about problem areas should decrease.

Hypothesis 2: The positive relationship between employees' tenacity and problemfocused voice is moderated by their perceptions of relational adversity - as reflected in low levels of (a) goal congruence and (b) trust-such that the relationship is stronger at higher levels of relational adversity.

\section{Moderating Role of Organizational Support for Change}

The expected value of tenacity for spurring problem-focused voice behaviors also might increase in conditions of high organizational adversity, such as when the organization offers limited support for change (Scott \& Bruce, 1994). Employees who perceive that their organization is rigid and not open to new ideas about how to do their jobs will be more motivated to allocate their personal energy to behaviors that might remove organizational hurdles that prevent them from meeting their job requirements (Quinn et al., 2012). For example, employees who believe that existing organizational procedures do not allow them to change the ways they work to meet preset performance standards may feel compelled to use their personal energy to find supporters who will help them lobby for greater job autonomy (De Clercq, Castañer, \& Belausteguigoitia, 2011). This invigorating effect of organizational adversity is consistent with the premises of COR theory. To the extent that employees feel threatened in their ability to find novel ways to fulfill work obligations, due to organizational rigidity, they will be particularly motivated to invest personal energy to seek resource gains that might accrue from pinpointing organizational malfunctioning (Boon \& Kalshoven, 2014; Hobfoll \& Shirom, 2000). Conversely, when employees do not experience organizational adversity, their tenacity should have less motivational value in terms of spurring extensive efforts to expose problem areas.

Similarly, when organizational decision making is perceived as rigid, employees may develop negative feelings toward their employer, because they have limited freedom to find 
novel ways to perform their job tasks (Scott \& Bruce, 1994). In this case, they may experience a stronger need to invest personal energy in sharing their frustration with colleagues, to diminish these negative feelings (Weiss \& Cropanzano, 1996). For example, speaking up about problem areas might trigger other organizational members to share their expertise or ways to perform adequately, even in the presence of organizational rigidity (Liang et al., 2012). Thus, applications of personal energy to these behaviors should be useful for overcoming the fear of underperformance due to this unfavorable organizational condition. Conversely, when faced with limited organizational resistance to change, employees have less need to allocate their personal energy to engaging colleagues in helping them reduce fears; the associated flexibility already makes them feel more positive about the ways in which they can meet their job requirements (Scott \& Bruce, 1994). The tenacity-problem-focused voice relationship thus should be weaker to the extent that employees have little need to draw support from other organizational members to cope with strict limitations on novel ways to perform their jobs.

Hypothesis 3: The positive relationship between employees' tenacity and their problemfocused voice is moderated by their perceptions of organizational adversity (low organizational support for change), such that the relationship is stronger at higher levels of organizational adversity.

This positive moderating effect of organizational adversity also should be particularly strong in conditions marked by high relational adversity, which suggests a three-way interaction among tenacity and the two sources of workplace adversity. When poor peer relationships discourage employees from asking for constructive feedback about how to meet their job requirements — whether due to incompatible goals or the fear that such feedback will be used against them later (De Clercq et al., 2013; Leana \& van Buren, 1999)—employees likely worry more about meeting their job obligations. According to AET, employees' belief that their 
organization does not allow for flexibility in how they undertake their job should be experienced as particularly stressful or threatening in situations with limited peer support, so their motivation to channel personal energy into pinpointing and solving organizational problems, which might mitigate these negative feelings, becomes extremely valuable (Weiss \& Cropanzano, 1996). That is, when the challenge of extreme organizational rigidity about how employees can undertake their job tasks gets exacerbated by unsupportive peer relationships, the allocation of personal energy to reporting problem areas becomes particularly important.

The reinforcing effect of the two types of workplace adversity also aligns with COR theory, which argues that initial resource losses can lead to negative resource spirals when different sources of resource loss operate simultaneously (Hobfoll, 1989; Wright \& Hobfoll, 2004). For our study, this logic suggests that when tenacious employees cannot draw from supportive peer relationships (one source of resource loss), their diminished ability to execute daily jobs due to organizational rigidity (another source of resource loss) becomes invigorated (Yuan \& Woodman, 2010). This escalation of negative experiences then increases their motivation to channel their personal energy into problem-focused voice behaviors, which might provide some novel insights into how to resolve the excessive workplace adversity (Liang et al., 2012). In contrast, when tenacious employees can count on their organizational peers to help them meet work demands, they will be less preoccupied with the presence of a rigid organizational climate that opposes change, so the anticipated value of allocating their personal energy to problem-focused voice behaviors should be mitigated (Wright \& Hobfoll, 2004).

Hypothesis 4: The invigorating effect of employees' perceptions of organizational adversity (low organizational support for change) on the positive relationship between their tenacity and problem-focused voice is moderated by their perceptions of relational adversity — as reflected in low levels of (a) goal congruence and (b) trust — such that the invigorating effect is stronger at higher levels of relational adversity. 


\section{Research Method}

\section{Sample and Data Collection}

Research that includes multiple organizations must account for the various external and competitive pressures that affect the time employees have available to engage in positive work behaviors (Hodson, 2002). To avoid the potential effects of unobserved differences in the external environment, we collected data from employees working for a single organization, namely, a smelting company in the northern part of Mexico. This organization, founded in 1979, manufactures custom steel parts for heavy equipment and machinery.

The data collection relied on two surveys, distributed in two rounds. First, we asked 120 randomly selected employees who worked either in a purely operational function (e.g., production, quality control, packaging) or a more supportive function (e.g., planning, accounting, sales) to assess their tenacity, the extent to which they shared similar goals with organizational peers, whether their peers could be trusted, and whether their organization supported change. The company's internal functioning, which encompasses an integrated system that seeks to optimize employee activities across the entire value chain, requires close interactions with organizational peers, so this empirical context is relevant for assessing constructs that assume some minimum level of work interdependence among employees. For example, an integrated quality control system requires employees to coordinate their efforts to meet the performance standards set by the company's top management, ranging from the input side (i.e., selection and processing of raw materials) all the way to the delivery of high-quality end products to industrial customers. Furthermore, the strong organizational culture that characterizes the company's internal functioning promotes strong collaboration among different functions and assigns significant weight to the collective contributions of employees to organizational effectiveness. 
We received 109 responses, for a response rate of 91\%, reflecting the strong support for this study by the organization's top management. The average respondent was 34 years of age and had worked for the organization for 7 years; $36 \%$ were women; $71 \%$ worked in an operational function; ${ }^{2}$ and $36 \%$ had managerial responsibilities (i.e., other employees reported to them).

Second, we surveyed the immediate supervisors (11 in total) of each first-round respondent to ask them about the extent to which these employees spoke out about problem areas in their organization. The number of respondents per supervisor ranged between 3 and 17.

The surveys, originally prepared in English, were translated into Spanish. To avoid cultural bias and ensure validity, the Spanish versions were back-translated into English (Brislin, Lonner, \& Thorndike, 1973). We pretested preliminary versions of the two surveys with two different sets of employees who did not participate in the actual data collection. By incorporating the feedback from these employees into the revised surveys, we increased the readability of the questions and the data quality. For both survey rounds, we guaranteed the participants complete confidentiality, repeatedly assured them that there were no right or wrong answers, and asked them to answer the questions as honestly as possible to minimize the possibility that their responses would be subject to social desirability or acquiescence biases (Spector, 2006). To mitigate the threat of social desirability biases even further, we also asked the respondents to return their surveys directly to us and ensured them that only aggregate results would be communicated with the organization after the study was complete.

\section{Measures}

\footnotetext{
2 The response rate for employees who worked in an operational function equaled 92\% (77 participants of 84 employees), and that for employees who worked in a supportive function was $89 \%$ (32 participants of 36 employees).
} 
The items for the four focal constructs came from previous research and used seven-point Likert scales, ranging from 1 ("strongly disagree") to 7 ("strongly agree").

Problem-focused voice. With our focus on employees' propensity to speak up about problem areas (instead of areas for improvement), we measured problem-focused voice with five items from Liang et al.'s (2012) scale of prohibitive voice, such as “This employee speaks up honestly about problems that might cause serious loss to the organization, even when/though dissenting opinions exist" and "This employee dares to voice opinions on things that might affect efficiency in the organization, even if that would embarrass others" (Cronbach's alpha $=.90)$.

Tenacity. We measured tenacity with five items used in previous research (Baum \& Locke, 2004). Employees indicated, for example, whether "I can think of many times when I persisted with work when others quit" and "I continue to work hard on tasks even when others oppose me" (Cronbach's alpha $=.80)$.

Moderating variables. To capture the presence of workplace adversity, either relationship (i.e., low goal congruence and low trust) or organizational (i.e., low organizational support for change), we assessed variables in contrasting directions, such that respondents indicated the extent to which their work environment was characterized by high levels of these features. First, we captured employees' goal congruence with organizational peers with four items used in previous research (De Clercq et al., 2013). Two example items were, "My colleagues and I share a similar vision regarding the organization's future" and "My colleagues and I think alike on most issues with respect to the organization" (Cronbach's alpha $=.79)$. Second, we assessed the extent to which employees believed their colleagues were trustworthy with five items used in prior literature on intra-firm trust (De Clercq et al., 2013). The employees indicated, for example, whether "My colleagues would not take advantage of me, even if the opportunity arose" and 
"My colleagues always keep the promises they make" (Cronbach's alpha $=.80)$. Third, to measure employees' perceptions of organizational support for change, we used four items adapted from Scott and Bruce's (1994) scale of innovation support, such as "My organization can be described as flexible" and "My organization is open to having its people come up with new suggestions" (Cronbach's alpha $=.80)$.

Control variables. We controlled for gender; men tend to exhibit higher voice rates than women (Detert \& Burris, 2007; LePine \& Van Dyne, 1998). We also controlled for age (in years), organizational tenure (in years), and hierarchical level (a binary variable equal to 1 when other employees reported to the respondents), because previous research suggests that more experienced or skilled employees may feel more confident about their ability to engage in voice (Burris, Detert, \& Chiaburu, 2008; Detert \& Burris, 2007; Tangirala \& Ramanujam, 2008b). Furthermore, we controlled for employees' job function, that is, whether their responsibilities were primarily operational (i.e., directly related to physical production) or supportive, with the former as the base category, and for their perceptions of work interdependence (one item that captured whether they depended on their colleagues to be able to do their work well). These last two control variables reflect our acknowledgment that employees' tendency to speak up about problem areas might depend on the nature of their job roles and the extent to which voice behaviors may be useful for other organizational members, respectively (Morrison, 2011).

We assessed the validity of the five focal constructs with a five-factor measurement model, using confirmatory factor analysis (Anderson \& Gerbing, 1988). The fit of the measurement model was good: $\chi^{2}{ }_{(185)}=266.83$, Tucker-Lewis index $=.91$, confirmatory fit index $=.94$, and root mean squared error of approximation $=.06$. In support of the convergent validity of the five constructs, the factor loadings of the respective items in the measurement model were 
significant ( $\mathrm{t}>2.0$; Gerbing \& Anderson, 1988). Moreover, we found discriminant validity among the constructs. For each pair generated from the constructs, we checked for any significant differences in the chi-square values of the constrained model (correlation between the constructs set to equal 1) versus the unconstrained model (correlation between the constructs was set free). The chi-square differences were significant for all the pairs $\left(\Delta \chi_{(1)}^{2}<.3 .84\right)$, which suggested discriminant validity (Anderson \& Gerbing, 1988).

\section{Results}

Table 1 contains the zero-order correlations and descriptive statistics. Table 2 provides the regression results. ${ }^{3}$ Model 1 included the control variables, Model 2 added tenacity, and Model 3 added the three moderators: goal congruence, trust, and organizational support for change. Models $4-6$ added the tenacity $\times$ goal congruence, tenacity $\times$ trust, and tenacity $\times$ organizational support for change interaction terms, respectively. Previous research indicates that it is appropriate to include multiple interaction terms separately, because the simultaneous inclusion of multiple interaction terms in one model can mask true moderating effects (Aiken \& West, 1991; De Clercq, Bouckenooghe, Raja, \& Matsyborska, 2014; Zahra \& Hayton 2008). Finally, Models 7 and 8 added the three-way interaction terms (tenacity $\times$ organizational support for change $\times$ goal congruence and tenacity $\times$ organizational support for change $\times$ trust), together with the two corresponding sets of constitutive two-way interactions, as recommended by Aiken and West (1991). For both the two- and three-way interaction terms, we adopted the wellestablished approach to mean center the product terms (Aiken \& West, 1991).

\footnotetext{
${ }^{3} \mathrm{An}$ assessment of the interclass correlation coefficients of goal congruence $(\mathrm{ICC}[1]=.04$ and ICC [2] $=.29)$, trust $(\operatorname{ICC}[1]=.05$ and ICC[2] $=.36$ ), and organizational support for change $(\operatorname{ICC}[1]=.02$ and $\operatorname{ICC}[2]=.20)$ - three constructs that arguably capture group-level phenomena - indicated that hierarchical linear modeling was not appropriate to test the study's hypotheses. The low ICC values might arise because the survey questions asked employees to assess their colleagues and organization in general, not a specific department. Therefore, we tested the hypotheses with ordinary least squares regression analyses.
} 
[Insert Tables 1 and 2 about here]

In support of our baseline prediction that employees' personal energy levels fuel their likelihood to speak up about problem areas, Model 2 revealed that tenacity related positively to problem-focused voice $(\beta=.595, p<.001)$, in strong support for Hypothesis 1 . Although they are beyond our theoretical focus, the results in Model 3 also indicated a direct positive effect of organizational support for change on problem-focused voice $(\beta=.282, p<.001)$, whereas the effects of goal congruence and trust were not significant.

Models 4-6 supported the hypothesized invigorating effects of adverse work conditions on the relationship between tenacity and problem-focused voice. That is, the relationship between tenacity and problem-focused voice was stronger at low levels of goal congruence $(\beta=-$ $.084, p<.05)$, trust $(\beta=-.137, p<.001)$, and organizational support for change $(\beta=-.242, p<$ .001 ), in support of Hypotheses 2a, 2b, and 3, respectively. To clarify the nature of these interactions, we plotted the effects of tenacity on problem-focused voice for high and low levels of the three moderators in Figure 2, Panels A to C. The plots indicate that the relationship of tenacity and problem-focused voice was stronger at low, compared with high, levels of the three moderators.

[Insert Figures 2A-C about here]

Moreover, we found support for Hypothesis 4a in the significant three-way interaction among tenacity, organizational support for change, and goal congruence in Model $7(\beta=.049, p$ $<.05)$. To clarify this interaction, we plotted the moderating effect of organizational support for change on the relationship between tenacity and problem-focused voice at high versus low levels of goal congruence in Figure 3. At low levels of goal congruence (Panel B), the two lines in the interaction plot were less parallel than those at high levels of goal congruence (Panel A). Thus, 
the importance of organizational adversity (i.e., low organizational support for change), in terms of invigorating the relationship between tenacity and problem-focused voice, was greater when it combined with high levels of relational adversity (i.e., low goal congruence). The results for Hypothesis 4b echoed those of Hypothesis 4a, though the effect was relatively weaker: The invigorating effect of organizational adversity (i.e., low organizational support for change) was somewhat stronger at low levels of trust $(\beta=.038, p<.10)$. Figure 4 provides additional detail about this three-way interaction effect. When trust was low (Panel B), the two lines in the interaction plot were less parallel than when trust was high (Panel A), indicating that the invigorating effect of organizational adversity on the relationship between tenacity and problemfocused voice was more salient when combined with high relational adversity.

[Insert Figures 4A-B about here]

\section{Discussion}

This study adds to voice behavior research by elaborating how employees' tenacity—or their tendency to allocate sustained goal-directed energy to their work tasks, irrespective of the challenge of these tasks (Baum \& Locke, 2004) —informs their propensity to speak up about problem areas. The limited prior attention to this issue is somewhat surprising, because the identification of problem areas can be perceived as confrontational by other organizational members and be met with significant criticism or resistance (LePine \& Van Dyne, 1998; Van Dyne et al., 2003), such that substantial personal energy is required to counter this challenge. Drawing from conservation of resources theory (Hobfoll, 2001) and affective events theory (Weiss \& Cropanzano, 1996), we investigated how the translation of tenacity into enhanced problem-focused voice behaviors - which should produce solutions to problem areas and thus enhance employees' ability to meet job requirements - is particularly salient when employees 
experience adverse work conditions that may instill the fear that they cannot perform their job tasks successfully. We focused on the challenges associated with the presence of limited goal sharing or trust in relationships with organizational peers (Leana \& van Buren, 1999) and limited organizational support for change (Yuan \& Woodman, 2010). We also argued for the presence of interdependent moderating effects of these sources of workplace adversity, such that the increased allocation of personal energy to problem-focused voice behavior when limited organizational support for change exists should be particularly strong when employees cannot draw on supportive peer relationships. Our research largely supports these theoretical arguments. Identifying problem areas can generate positive results for the organization and idea proponents (Parker, 1993; Seibert et al., 2001; Van Dyne \& LePine, 1998). Yet such problemfocused voice also consumes significant energy and creates challenges related to others' resistance to any change associated with the anticipated solutions to the problems (Liang et al., 2012). These challenges are mitigated for employees who can draw on their own high tenacity levels. Consistent with COR theory, employees who are persistent and have a long-term focus when allocating personal energy to challenging work activities, irrespective of the resistance that these activities may encounter, are more likely to speak up about problem areas, because they anticipate significant performance gains from their activities (Boon \& Kalshoven, 2014; Hobfoll, 2001). The positive relationship between tenacity and problem-focused voice complements previous research that suggests conscientiousness stimulates voice behaviors in general (Crant et al., 2011; LePine \& Van Dyne, 2001). Conscientiousness refers to the tendency of hard-working employees to be dependable and in control of their jobs (Crant et al., 2011; Duckworth et al., 2007); tenacity instead has a longer-term focus and is particularly useful for undertaking challenging behaviors that can generate significant, sustained resistance (Baum \& Locke, 2004), 
such as reports about organizational failures that are perceived as direct threats to those organizational members who are responsible for the failures (Liang et al., 2012).

In addition, this positive effect of tenacity on problem-focused voice is invigorated when employees believe the resulting performance gains will protect them against underperformance due to adverse workplace conditions, as manifested in unfavorable relationships with colleagues or a rigid organizational climate. The invigorating effects of these sources of workplace adversity follow the COR argument that the anticipated value of personal resource endowments for spurring additional resource or performance gains (through finding solutions to organizational problems) increases in the presence of possible resource drainage by adverse work conditions (Hobfoll \& Lilly, 1993; Hobfoll \& Shirom, 2000). When employees believe that their peers do not agree with them about where the organization is heading (low goal congruence), perceive that these peers would try to take advantage of them to achieve personal interests (low trust), or sense that their organization does not grant them much flexibility in terms of how they do their jobs (low organizational support for change), it is more important for them to channel their personal energy into voice activities that expose problem areas in their organization. Similarly, and consistent with AET, the performance gains that tenacious employees hope to achieve with their problem-focused voice behaviors are particularly instrumental when these behaviors can help overcome the negative feelings that employees experience when confronted with poor peer relationships or rigid organizational environments (Weiss \& Cropanzano, 1996).

Finally, this study reveals that the usefulness of tenacity for increased problem-focused voice is particularly salient when the two sources of workplace adversity (relational and organizational) operate in conjunction (Wright \& Hobfoll, 2004). When employees cannot rely on supportive peer relationships, the challenges of a rigid organizational environment seem 
greater (Cohen \& Wills, 1985), and tenacious employees become even more eager to leverage their personal energy to pinpoint problem areas, in the hope of continuing to meet their job requirements, despite the severe workplace adversity that they encounter. In contrast, when employees can draw from supportive peer relationships, marked by high levels of goal congruence and trust, the need to draw from their tenacity to speak up about problem areas because of rigid organizational decision making gets subdued.

Overall, these results are significant in that they establish a more complete understanding of how voice behaviors focused on problem situations emerge within organizations (Morrison, 2011). An important but underexplored facet of voice behaviors refers to attempts to bring problem situations into the open, as opposed to providing suggestions about how the organization can be improved in general (Liang et al., 2012). Such problem-focused voice tends to be more disruptive and encounter more significant resistance, particularly by those who feel threatened directly by that form of voice. Our results add to extant voice literature by specifying the concurrent roles that employees' tenacity levels and distinct sources of work adversity (poor peer relations and a rigid organizational climate) have for stimulating problem-focused voice, as well as revealing the individual and combined influences of these sources of workplace adversity on the anticipated usefulness of allocating sustained personal energy to problem-focused voice.

\section{Limitations and Future Research Directions}

This study has some shortcomings that suggest research opportunities. First, some caution is needed in terms of causality; the tenacity-problem-focused voice relationship could be susceptible to reverse causality. Employees who pinpoint and speak up about problem areas may feel revitalized by these activities, such that their tenacity levels increase (Parker, 1993; Quinn et al., 2012). Although our hypotheses were anchored in well-established theoretical frameworks 
(COR and AET), additional studies with longitudinal designs could investigate the causal processes that link tenacity with problem-focused voice behaviors more explicitly, as well as the contingency conditions that influence this process. Second, though previous research indicates that the personal characteristic of grit, akin to tenacity, has incremental predictive power over and above that of conscientiousness (Duckworth et al., 2007; Duckworth \& Quinn, 2009; Suzuki et al., 2015), additional research could investigate whether our findings hold when controlling for conscientiousness or other relevant personal characteristics, such as employees' self-efficacy (Bandura, 1989) or resilience (Luthans, Avolio, Avey, \& Norman, 2007).

Third, our choice to focus on voice - instead of alternative behaviors such as exit, loyalty, or neglect - was driven by the recognition that, because of its proactive and constructive nature, this behavior may benefit most from employees' tenacity or sustained allocation of goal-directed energy to work tasks ( $\mathrm{Li} \& \mathrm{Li}, 2012$; Rusbult et al., 1988). Still, future research could consider a more comprehensive set of work behaviors and investigate, for example, whether the likelihood of exit is significantly higher among employees who exhibit low tenacity levels. Further research also could complement the quantitative approach we have applied with qualitative approaches that provide more detailed information about the nature of the voice activities and thereby explore, for example, how the anticipated impact of solutions to the identified problems differs, depending on whether the problems are situated in core or more supportive activities in the value chain.

Fourth, to expand our theoretical framework in other directions, it might be interesting to investigate whether and how employees' problem-focused voice, as informed by their tenacity levels, influences their ability to meet their job requirements, as well as how the moderators studied herein affect this causal process. 
Fifth, with our focus on three contingency factors, we ignore other factors that might invigorate the positive relationship between tenacity and problem-focused voice. Further research could consider the impact of other sources of relational adversity, such as interpersonal conflict (Ilies, Johnson, Judge, \& Keeney, 2011) or excessive task interdependence (Van der Vegt, Emans, \& van de Vliert, 2000), as well as workplace adversity due to decision-making styles, such as perceptions of low procedural justice (Tangirala \& Ramanujam, 2008a) or selfserving behaviors (Abbas, Raja, Darr, \& Bouckenooghe, 2014). To the extent that employees believe organizational decision making is unfair or marked by destructive political games, the anticipated value of allocating their sustained personal energy to activities to diminish the negative influences of such dysfunctional decision making may increase.

\section{Practical Implications}

This study reveals how tenacity stimulates employees' propensity to speak up about organizational problems, as well as why this positive influence is particularly potent in the presence of significant workplace adversity. Problem-focused voice behaviors can be very beneficial for organizations, yet the barriers to employees to engage in such behaviors are munificent, including resistance by organizational members who do not want to be held responsible for problems or the limited time available to engage in energy-consuming voice behaviors that bring organizational failures to the surface. Identifying a critical personal characteristic, such as tenacity, that enhances problem-focused voice despite these challenges thus has significant practical relevance. Our findings suggest that organizations with an interest in stimulating reports about problem situations in their ranks should attempt to hire employees who are perseverant and maintain a long-term approach toward allocating personal energy to challenging work activities, however risky these activities might be. Furthermore, training 
tenacious employees to allocate their personal energy to difficult, change-invoking work activities, such as problem-focused voice, should enhance organizations' ability to cope successfully with any resistance to these activities.

Our investigation of the interplay between tenacity and workplace adversity for predicting problem-focused voice behavior also has practical relevance. This study reveals some of the circumstances in which tenacity is a more important means through which employees speak about problem areas (Liang et al., 2012). Organizations can benefit most from the voice behaviors of employees who are perseverant and relentless in their work efforts when their past work trajectory has featured poor peer relationships or rigid decision making — features that might not be reversed easily. That is, to the extent that the organization's historical functioning has created significant workplace adversity, marked by poor peer relationships or rigid organizational decision making, targeted initiatives that invest company resources in training efforts geared at leveraging tenacity into problem-focused voice may be particularly useful. In addition to the role of workplace adversity, other useful initiatives may also encourage employees to apply their personal energy to voice behaviors, such as financial reward systems that directly compensate employees for any tangible organizational improvements that emerge from their problem-focused voice efforts, or provisions of intangible rewards that recognize these efforts as exemplary behaviors or role models for other organizational members (Morrison, 2011; Ryan \& Deci, 2000). Ultimately, organizations whose history is marked by adverse social relationships and limited decision-making flexibility can benefit to the extent that they can channel the personal energy reservoirs of their employees into activities targeted at pinpointing and resolving problem situations.

\section{Conclusion}


This study has addressed questions of how and when employees' tenacity is more likely to increase their propensity to speak up about organizational problems. Tenacity fuels problemfocused voice, and this process is more prominent when employees encounter adverse situations in their relationships with peers, characterized by low levels of goal congruence and trust, and when their organization does not support change. We hope this work functions as a catalyst for further studies of how organizations can leverage the personal resources of their employee bases effectively, especially in the presence of adverse work conditions. 


\section{References}

Abbas, M., Raja, U., Darr, W., \& Bouckenooghe, D. (2014). Combined effects of perceived politics and psychological capital on job satisfaction, turnover intentions, and performance. Journal of Management, 40, 1813-1830.

Aiken, L.S., \& West, S.G. (1991). Multiple regression: Testing and interpreting interactions. Newbury Park, CA: Sage.

Allison, T.H., McKenny, A.F., \& Short, J.C. (2013). The effect of entrepreneurial rhetoric on microlending investment: An examination of the warm-glow effect. Journal of Business Venturing, 28, 690-707

Anderson, J.C., \& Gerbing, D.W. (1988). Structural equation modeling in practice: A review and recommended two-step approach. Psychology Bulletin, 1033, 411-423.

Argyris, C., \& Schon, D. (1978). Organizational learning: A theory of action approach, Reading, MA: Addison Wesley.

Avery, D. R., \& Quinones, M. A. (2002). Disentangling the effects of voice: The incremental roles of opportunity, behavior, and instrumentality in predicting procedural fairness. Journal of Applied Psychology, 87, 81-99.

Avila, R.A., \& Fern, E.F. (1986). The selling situation as a moderator of the personality-sales performance relationship: an empirical investigation. Journal of Personal Selling \& Sales Management, 6, 53-63.

Bandura, A. (1989). Human agency in social cognitive theory. American Psychologist, 44, 11751184.

Bass, B. M., \& Stogdill, R. M. (1990). Bass \& Stogdill's handbook of leadership: Theory, research, and managerial implications. New York: Free Press.

Baum, J.R., \& Locke, E.A. (2004). The relationship of entrepreneurial traits, skill, and motivation to subsequent venture growth. Journal of Applied Psychology, 89, 587-598.

Boon, C., \& Kalshoven, K. (2014). How high-commitment HRM relates to engagement and commitment: The moderating role of task proficiency. Human Resource Management, 53, 403-420.

Brislin, R.W., Lonner, W., \& Thorndike, R.M. (1973). Cross-cultural research methods. New York: John Wiley \& Sons.

Burris, E.R., Detert, J.R., \& Chiaburu, D.S. (2008). Quitting before leaving: The mediating effects of psychological attachment and detachment on voice. Journal of Applied Psychology, 93, 912-922.

Cohen, S., \& Wills, T. A. (1985). Stress, social support, and the buffering hypothesis. Psychological Bulletin, 98, 310-357.

Crant, J.M., Kim, T.-Y., \& Wang, J. (2011). Dispositional antecedents of demonstration and usefulness of voice behavior. Journal of Business and Psychology, 26, 285-297.

De Clercq, D., Bouckenooghe, D., Raja, U., \& Matsyborska, G. (2014). Servant leadership and work engagement: The contingency effects of leader-follower social capital. Human Resource Development Quarterly, 25, 183-212.

De Clercq, D., Castañer, X., \& Belausteguigoitia, I. (2011). Entrepreneurial initiative selling within organizations: Toward a more comprehensive motivational framework. Journal of Management Studies, 48, 1269-1290. 
De Clercq, D., Dimov, D., \& Thongpapanl, N. (2013). Organizational social capital, formalization, and internal knowledge sharing in entrepreneurial orientation formation. Entrepreneurship Theory and Practice, 37, 505-537.

Detert, J.R., \& Burris, E.R. 2007. Leadership behavior and employee voice: Is the door really open? Academy of Management Journal, 50, 869-884.

Duckworth, A. L., Peterson, C., Matthews, M. D., \& Kelly, D. R. (2007). Grit: Perseverance and passion for long-term goals. Journal of Personality and Social Psychology, 92, 1087-1101.

Duckworth, A., \& Quinn, P. D. (2009). Development and validation of the Short Grit Scale (Grit-S ). Journal of Personality Assessment, 91, 166-174.

Fuller, J. B., Barnett, T., Hester, K., Relyea, C., \& Frey, L. (2007). An exploratory examination of voice behavior from an impression management perspective. Journal of Managerial Issues, 19, 134-151.

Gerbing, D.W., \& Anderson, J.C. (1988). An updated paradigm for scale development incorporating unidimensionality and its assessment. Journal of Marketing Research, 25, 186-192.

Goldberg, C.B., Clark, M.A., \& Henley, A.B. (2011). Speaking up: A conceptual model of voice responses following the unfair treatment of others in non-union settings. Human Resource Management, 50, 75-94.

Greenberger, D.B., \& Strasser, S. 1986. The development and application of a model of personal control in organizations. Academy of Management Review, 11, 164-177.

Hirschman, A.O. (1970). Exit, Voice and Loyalty, Responses to Decline in Firms, Organizations, and States, Cambridge, MA: Harvard University Press.

Hobfoll, S.E. (1989). Conservation of resources. A new attempt at conceptualizing stress. American Psychologist, 44, 513-524.

Hobfoll, S.E. (2001). The influence of culture, community, and the nested-self in the stress process: Advancing conservation of resource theory. Applied Psychology: An International Review, 50, 337-369.

Hobfoll, S.E. (2011). Conservation of resource caravans and engaged settings. Journal of Occupational and Organizational Psychology, 84, 116-122.

Hobfoll, S.E., \& Lilly, R.S. (1993) Resource conservation as a strategy for community psychology. Journal of Community Psychology, 21, 128-148.

Hobfoll, S. E., \& Shirom, A. (2000). Conservation of resources theory: Applications to stress and management in the workplace. In R.T. Golembiewski (Ed.), Handbook of Organization Behavior ( $2^{\text {nd }}$ ed., pp. 57-81). New York: Dekker.

Hodson, R. (2002). Management citizenship behavior and its consequences. Work and Occupations, 29, 64-96.

House, R. J., \& Shamir, B. (1993). Toward the integration of transformational, charismatic and visionary theories of leadership. In M. Chemers \& R. Ayman (Eds.), Leadership theory and research: Perspectives and directions (pp. 81-107). San Diego, CA: Academic Press.

Ilies, R., Johnson, M. D., Judge, T. A., \& Keeney, J. (2011). A within-individual study of interpersonal conflict as a work stressor: Dispositional and situational moderators. Journal of Organizational Behavior, 32, 44-64.

Jones, D.A. (2009). Getting even with one's supervisor and one's organization: relationships among types of injustice, desires for revenge, and counterproductive work behaviors. Journal of Organizational Behavior, 30, 525-542. 
Leana, C. R., \& van Buren, H.J., III (1999). Organizational social capital and employment practices. Academy of Management Review, 24, 538-555.

LePine, J.A., \& Van Dyne, L. (1998). Predicting voice behavior in work groups. Journal of Applied Psychology: An International Review, 83, 853-868.

LePine, J.A., \& Van Dyne, L. (2001). Voice and cooperative behavior as contrasting forms of contextual performance: Evidence of differential relationships with big five personality characteristics and cognitive ability. Journal of Applied Psychology, 86, 326-336.

Liang, J., Farh, C.I.C., \& Farh, J. (2012). Psychological antecedents of promotive and prohibitive voice: A two-wave examination. Academy of Management Journal, 55, 71-92.

Luthans, F, Avolio, B.J., Avey, J.B., \& Norman, S.M. (2007). Positive psychological capital: Measurement and relationship with performance and satisfaction. Personnel Psychology, 60, 541-572.

Maynes, T.D., \& Podsakoff, P.M. (2014). Speaking more broadly: An examination of the nature, antecedents, and consequences of an expanded set of employee voice behaviors. Journal of Applied Psychology, 99, 87-112.

Milliken, F.J., Morrison, E.W., \& Hewlin, P. (2003). An exploratory study of employee silence: Issues that employees don't communicate upward and why. Journal of Management Studies, 40, 1453-1476.

Morrison, E.W. (2011). Employee voice behavior: Integration and directions for future research. Academy of Management Annals, 5, 373-412.

Morrison, E.W., \& Milliken, F. J. (2000). Organizational silence: A barrier to change and development in a pluralistic world. Academy of Management Review, 25, 706-725.

Nahapiet, J., \& Ghoshal, S. (1998). Social capital, intellectual capital, and the organizational advantage. Academy of Management Review, 23, 242-268.

Parker, L.E.(1993). When to fix it and when to leave: Relationships among perceived control, self-efficacy, dissent, and exit. Journal of Applied Psychology, 78, 949-959.

Pinto, M.B., Pinto, J.K., and Prescott, J.E. (1993). Antecedents and consequences of project team cross-functional cooperation. Management Science, 39, 1281-97.

Quinn, R.W., Spreitzer, G.M., \& Lam, C.F. (2012). Building a sustainable model of human energy in organizations: Exploring the critical role of resources. Academy of Management Annals, 6, 337-396.

Rousseau, D.M., Sitkin, S.B., Burt, R.S., \& Camerer, C. (1998). Not so different after all: a cross-discipline view of trust. Academy of Management Review, 23, 393-404.

Rusbult, C.E., Farrell, D., Rogers, G., \& Mainus, A.G. (1988). Impact of exchange variables on exit, voice, loyalty, and neglect: An integrative model of responses to declining job satisfaction. Academy of Management Journal, 31, 599-627.

Ryan, R.M., \& Deci, E.L. (2000). Self-determination theory and the facilitation of intrinsic motivation, social development, and well-being. American Psychologist, 55, 68-78.

Scott, S. G., \& Bruce, R. A. (1994). Determinants of innovative behavior: A path model of individual innovation in the workplace. Academy of Management Journal, 37, 580-607.

Seibert, S.E., Kraimer, M.L., \& Crant, J.M. (2001). What do proactive people do? A longitudinal model linking proactive personality and career success. Personnel Psychology, 54, 845874.

Si, S., \& Li, Y. (2012). Human resource management practices on exit, voice, loyalty, and neglect: organizational commitment as a mediator. The International Journal of Human Resource Management, 23, 1705-1716. 
Song, L.Z., \& Song, M. (2010). The role of information technologies in enhancing R\&Dmarketing integration: An empirical investigation. Journal of Product Innovation Management, 27, 382-401.

Spector, P.E. (2006). Method variance in organizational research: Truth or urban legend? Organizational Research Methods, 9, 221-232.

Suzuki, Y., Tamesue, D., Asahi, K., \& Ishikawa, Y. (2015). Grit and work engagement: A crosssectional study. PLoS One, 10(9), e0137501, doi: 10.1371/journal.pone.0137501.

Tangirala, S., Kamdar, D., Venkataramani, V., \& Parke, M.R. (2013). Doing right versus getting ahead: The effects of duty and achievement orientations on employees' voice. Journal of Applied Psychology, 98, 1040-1050.

Tangirala, S., \& Ramanujam, R. (2008a). Employee silence on critical work issues: The cross level effects of procedural justice climate. Personnel Psychology, 61, 37-68.

Tangirala, S., \& Ramanujam, R. (2008b). Exploring nonlinearity in employee voice: The effects of personal control and organizational identification. Academy of Management Journal, 51, 1189-1203.

Van der Vegt, G.S., Emans, B., \& van de Vliert, E. (2000). Team members' affective responses to patterns of intragroup interdependence and job complexity. Journal of Management, 4, 633-655

Van Dyne, L., Ang, S., \& Botero, I.C. (2003). Conceptualizing employee silence and employee voice as multidimensional constructs. Journal of Management Studies, 40, 1359-1392.

Van Dyne, L., Cummings, L.L., \& McLean Parks, J. (1995). Extra-role behaviors: In pursuit of construct and definitional clarity. In B. M. Staw, \& L. L. Cummings (Eds.), Research in organizational behavior, vol. 17: 215-285. Greenwich, CT: JAI.

Van Dyne, L., \& LePine, J. A. (1998). Helping and voice extra-role behavior: Evidence of construct and predictive validity. Academy of Management Journal, 41, 108-119.

Venkataramani, V., \& Tangirala, S. (2010). When and why do central employees speak up? An examination of mediating and moderating variables. Journal of Applied Psychology, 95, 582-591.

Weiss, H. M., \& Beal, D. J. (2005). Reflections on affective events theory. In N. M. Ashkanasy, W. J. Zerbe, \& C. E. J. Ha rrtel. (Eds.). The effect of affect in organizational settings (Vol. 1, pp. 1-21). San Diego CA: Emerald.

Weiss, H. M., \& Cropanzano, R. (1996). Affective events theory: A theoretical discussion of the structure, causes and consequences of affective experiences at work. Research in Organizational Behavior, 18, 1-74.

Weiss, H. M., Suckow, K., \& Cropanzano, R. (1999). Effects of justice conditions on discrete emotions. Journal of Applied Psychology, 84, 786-794.

Wells, C.V., \& Kipnis, D. (2001). Trust, dependency, and control in the contemporary organization. Journal of Business and Psychology, 15, 593-603.

Wright, T.A., \& Hobfoll, S.E. (2004), Commitment, psychological well-being and job performance: An examination of conservation of resources (COR) theory and job burnout. Journal of Business and Management, 9, 389-406.

Yuan, F., \& Woodman, R. (2010). Innovative behavior in the workplace: The role of performance and image outcome expectations. Academy of Management Journal, 53, 323342.

Zahra, S., \& Hayton, J.C. (2008). The effect of international venturing on firm performance: The moderating influence of absorptive capacity. Journal of Business Venturing, 23, 195-220. 
Figure 1. Conceptual model

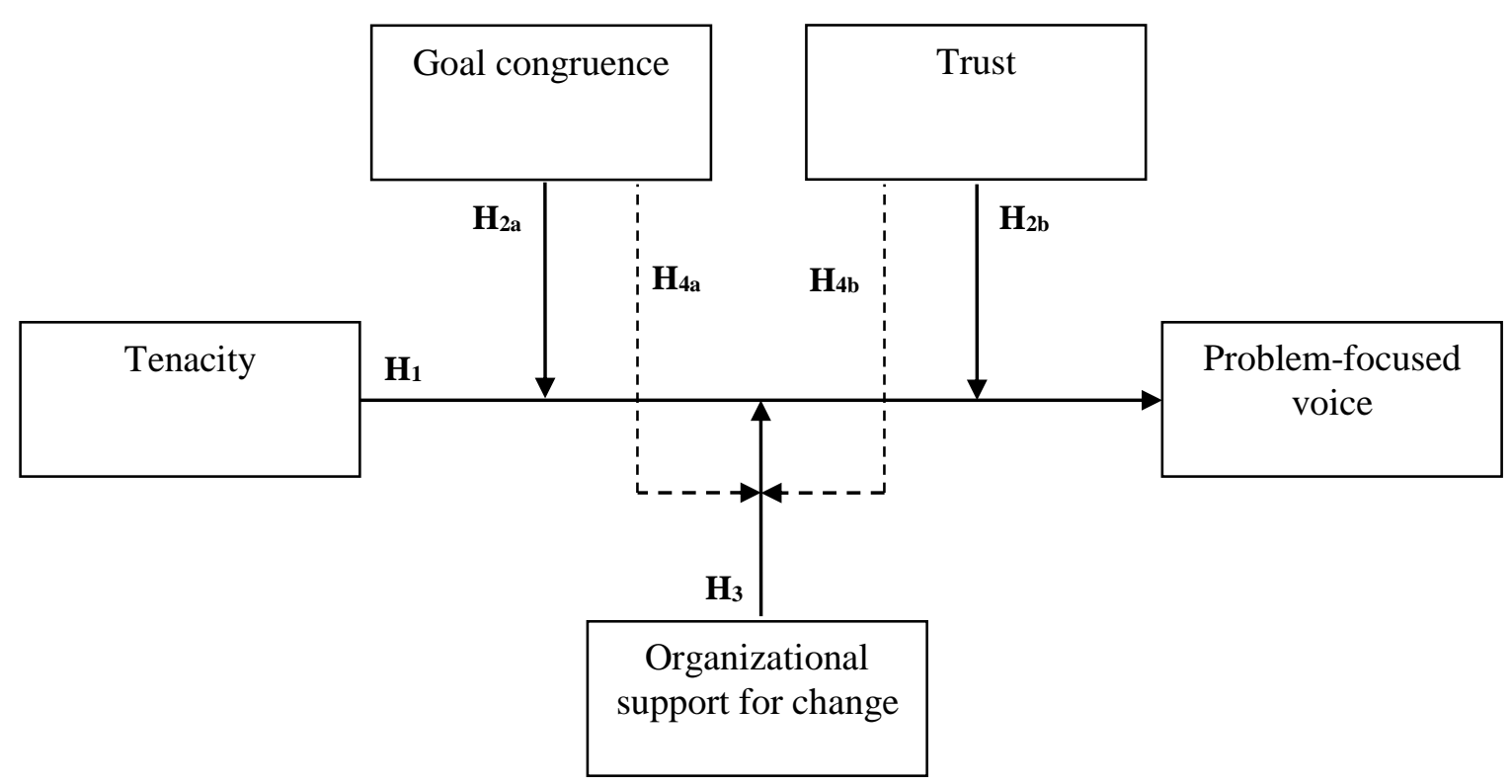


Figure 2. Two-way interaction effects

A. Goal congruence on the relationship between tenacity and problem-focused voice

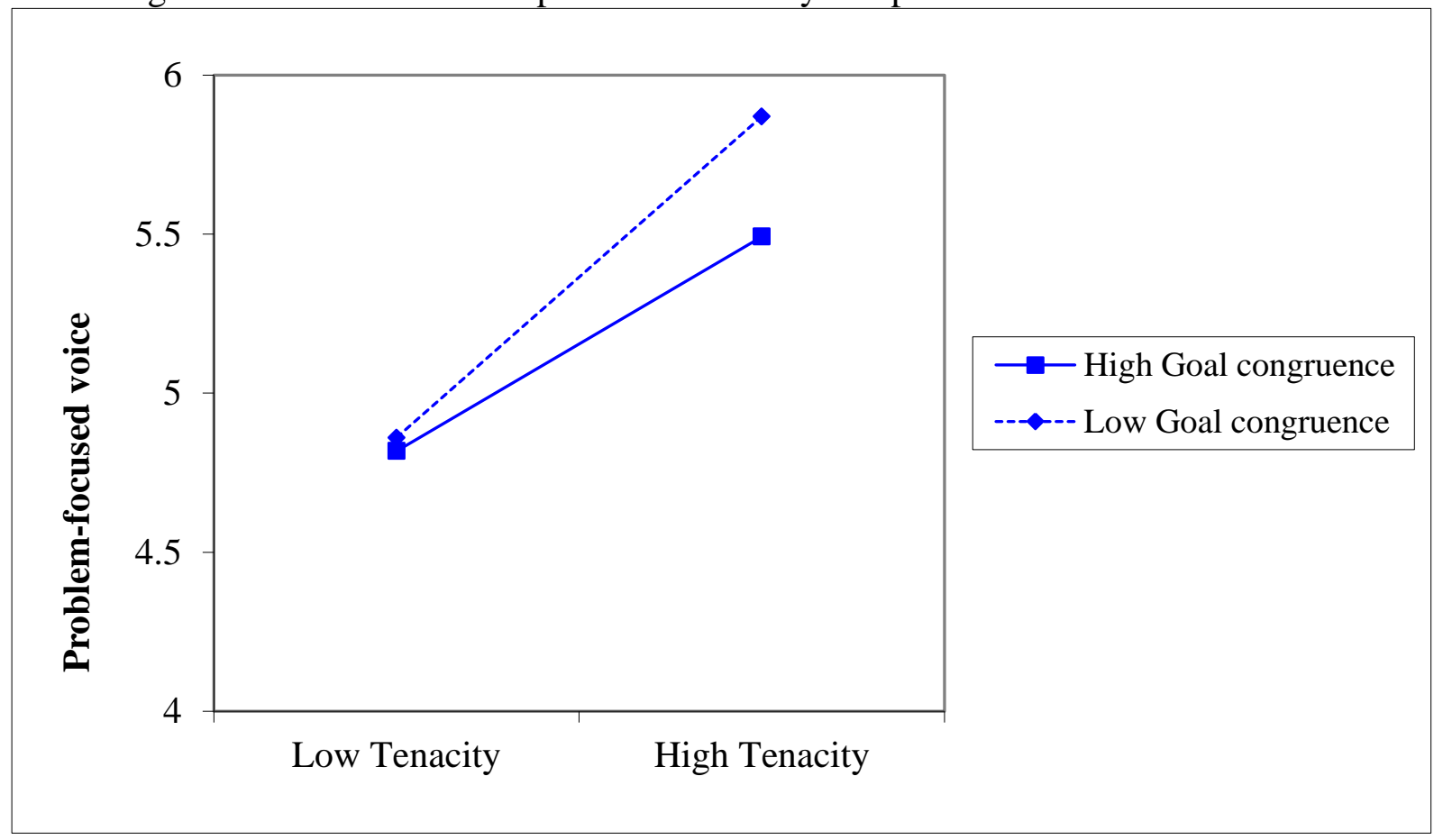

B. Trust on the relationship between tenacity and problem-focused voice

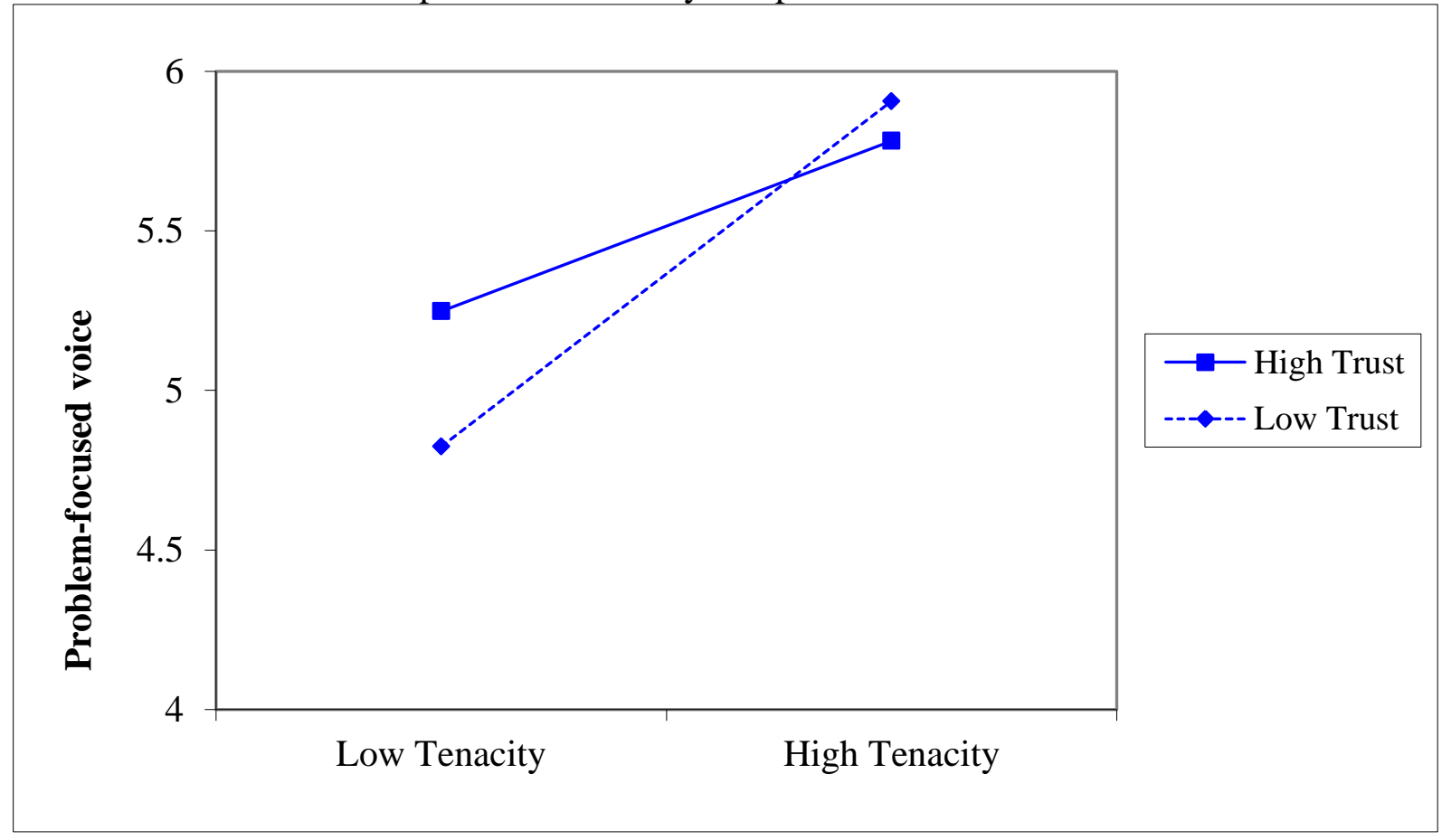


C. Organizational support for change on the relationship between tenacity and problem-focused voice

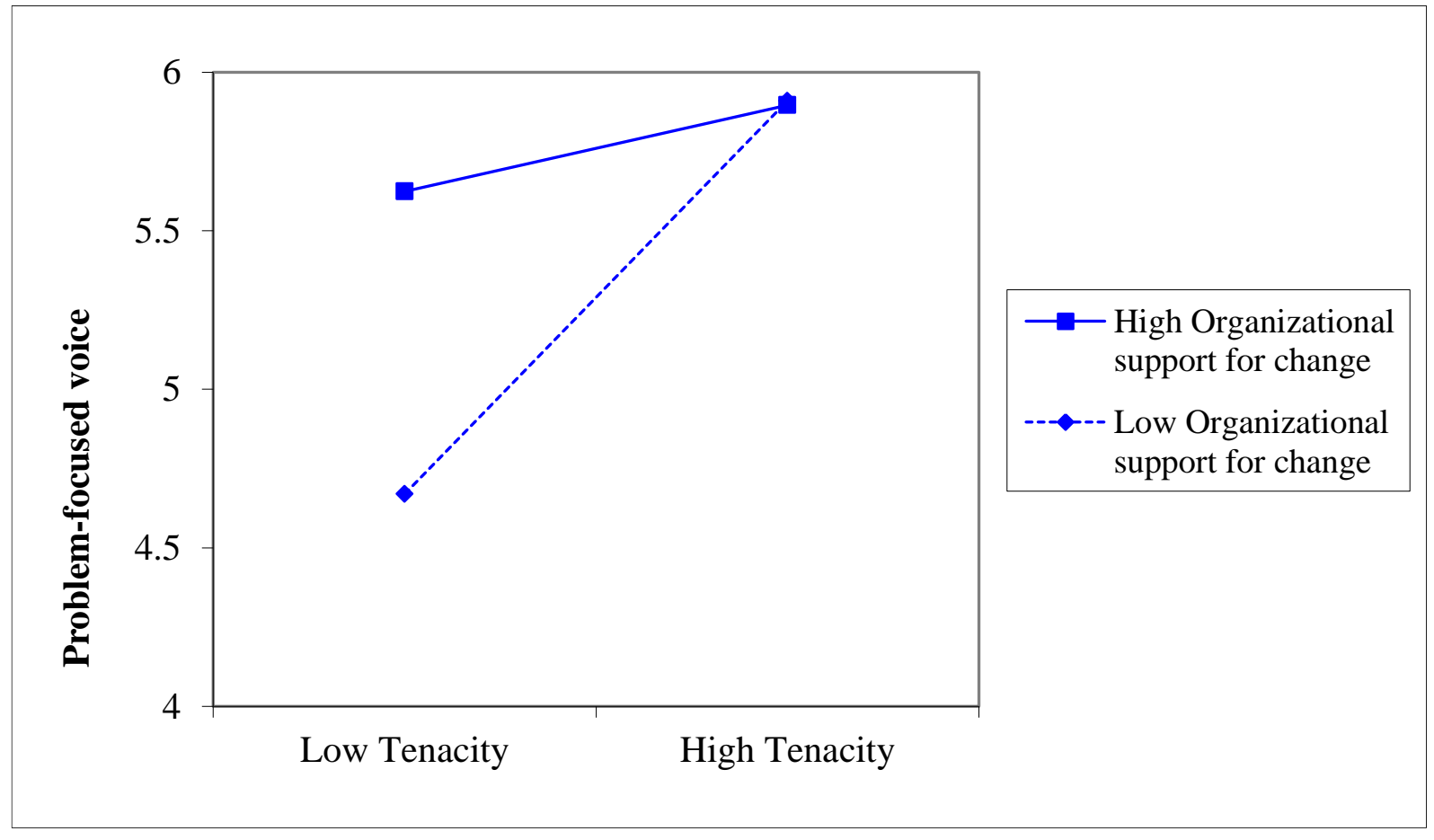


Figure 3. Three-way interaction effect

A. Organizational support for change on the relationship between tenacity and problem-focused voice at high goal congruence

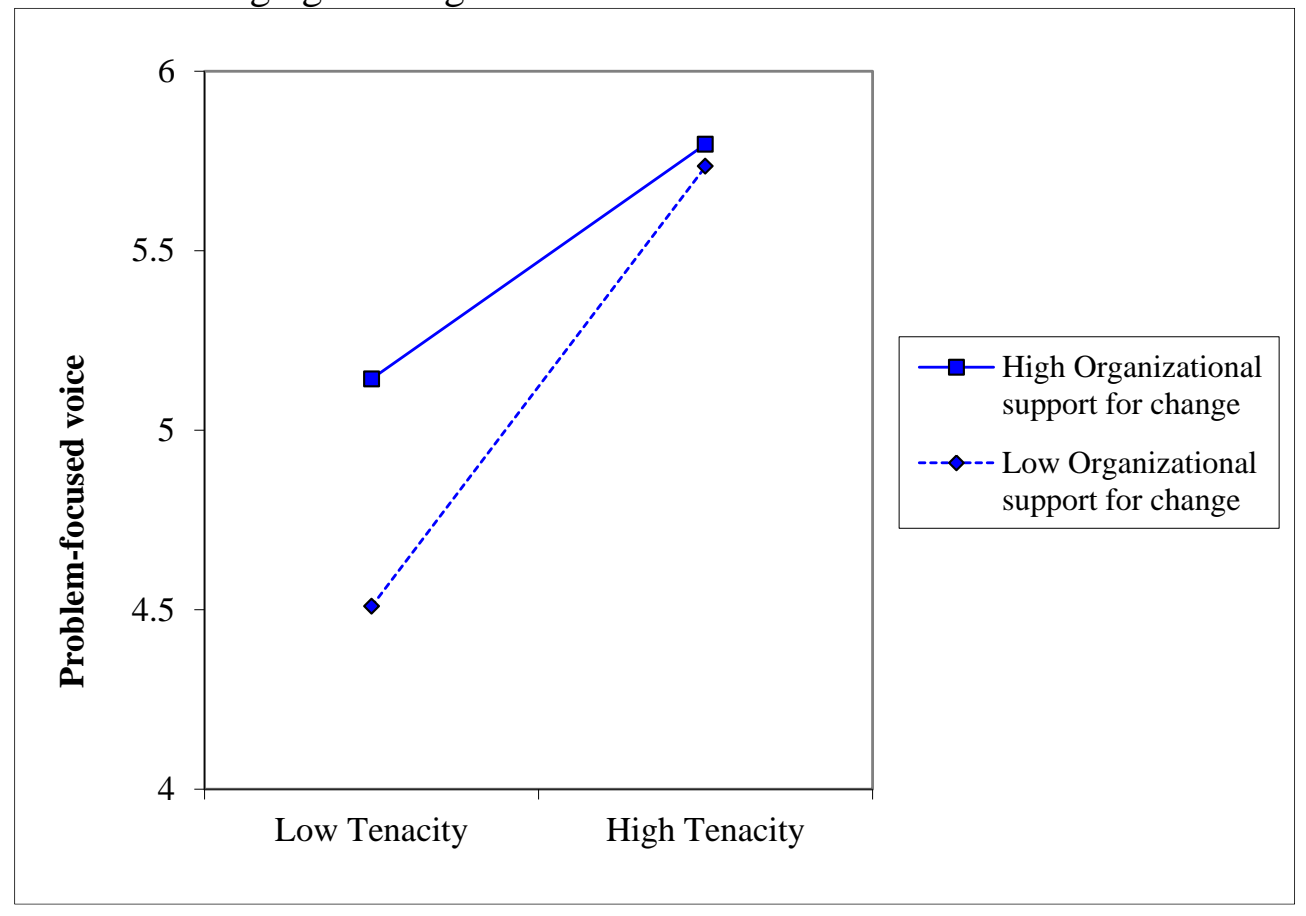

B. Organizational support for change on the relationship between tenacity and problem-focused voice at low goal congruence

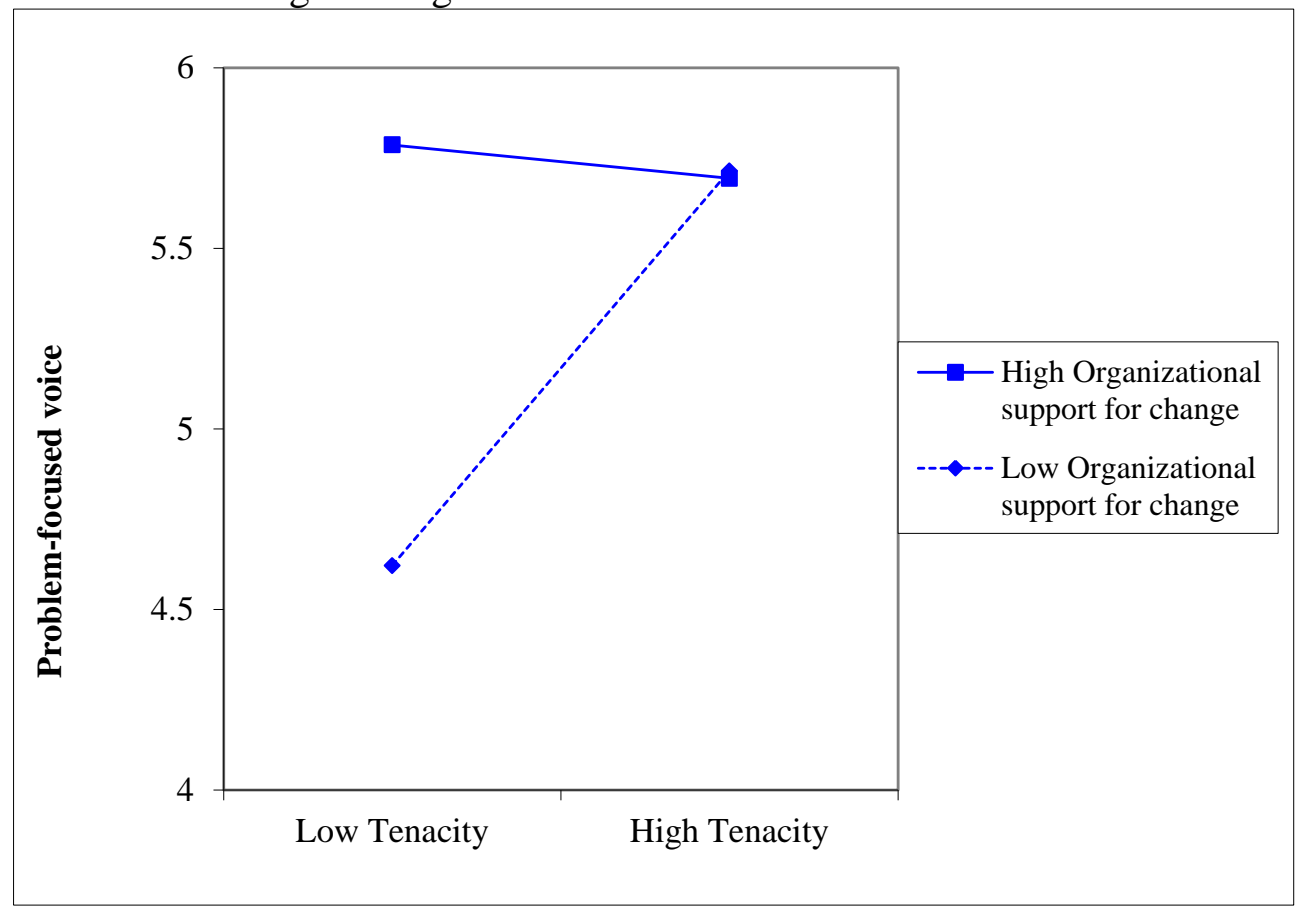


Figure 4. Three-way interaction effect

A. Organizational support for change on the relationship between tenacity and problem-focused voice at high trust

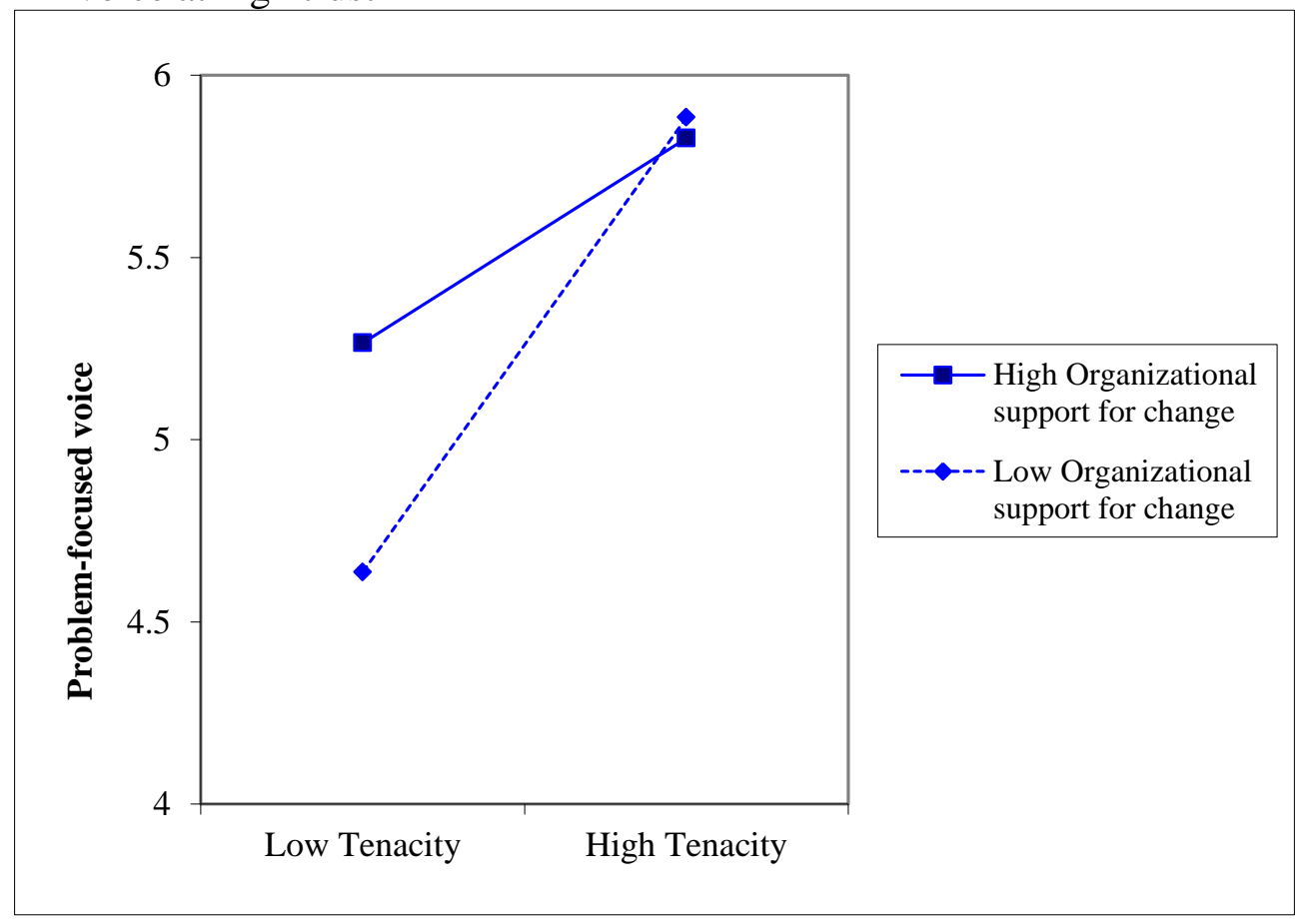

B. Organizational support for change on the relationship between tenacity and problem-focused voice at low trust

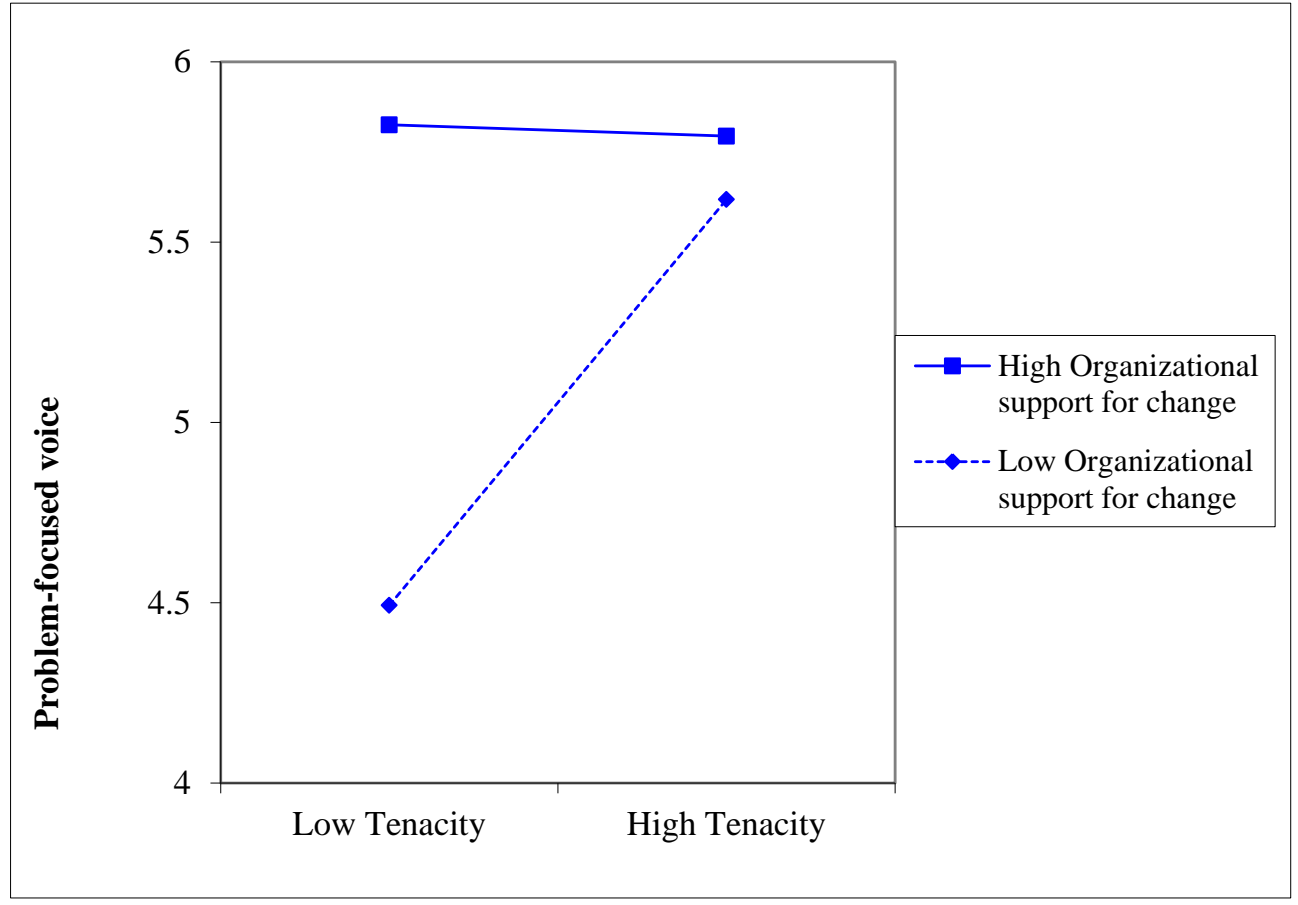


TABLE 1

Correlation table and descriptive statistics

\begin{tabular}{|c|c|c|c|c|c|c|c|c|c|c|c|}
\hline & 1 & 2 & 3 & 4 & 5 & 6 & 7 & 8 & 9 & 10 & 11 \\
\hline 1. Problem-focused voice & & & & & & & & & & & \\
\hline 2. Tenacity & $.575^{* *}$ & & & & & & & & & & \\
\hline 3. Goal congruence & $.311 * *$ & $.442 * *$ & & & & & & & & & \\
\hline 4. Trust & $.252 * *$ & $.279 * *$ & $.563 * *$ & & & & & & & & \\
\hline $\begin{array}{l}\text { 5. Organizational support for } \\
\text { change }\end{array}$ & $.508 * *$ & $.356^{* * *}$ & $.490 * *$ & $.396 * *$ & & & & & & & \\
\hline 6. Gender & -.057 & -.140 & -.137 & .000 & -.140 & & & & & & \\
\hline 7. Age ( $1=$ female $)$ & .169 & $.272 * *$ & .128 & .051 & .048 & $-.355^{* *}$ & & & & & \\
\hline 8. Organizational tenure & .091 & .122 & .030 & .071 & .018 & $-.203 *$ & $.548 * *$ & & & & \\
\hline $\begin{array}{l}\text { 9. Hierarchical level }(1= \\
\text { managerial })\end{array}$ & .093 & .087 & .037 & .051 & -.009 & $-.238 *$ & .075 & .126 & & & \\
\hline $\begin{array}{l}\text { 10. Job function }(1= \\
\text { operational })\end{array}$ & .071 & .074 & .135 & .125 & $.197 *$ & -.023 & $-.238 *$ & $-.197 *$ & .061 & & \\
\hline 11. Work interdependence & .070 & .160 & $.196 *$ & $.410 * *$ & .132 & .061 & -.005 & -.012 & -.023 & .140 & \\
\hline Mean & 5.434 & 5.167 & 5.305 & 5.044 & 4.756 & .358 & 33.908 & 6.551 & .358 & .706 & 5.171 \\
\hline SD & .993 & .936 & 1.364 & 1.317 & 1.248 & .482 & 8.912 & 5.584 & .482 & .458 & 2.132 \\
\hline
\end{tabular}

Notes: $\mathrm{N}=109$.

$* * p<.01 . * p<.05$. 
TABLE 2

Regression results (dependent variable: problem-focused voice)

\begin{tabular}{|c|c|c|c|c|c|c|c|c|}
\hline & Model 1 & Model 2 & Model 3 & Model 4 & Model 5 & Model 6 & Model 7 & Model 8 \\
\hline Gender $(1=$ female $)$ & -.152 & -.070 & .000 & .023 & .021 & .051 & .103 & .153 \\
\hline Age & .011 & -.008 & -.004 & -.003 & -.002 & .000 & .002 & .004 \\
\hline Organizational tenure & .018 & .020 & .018 & .016 & $.021+$ & .008 & .009 & .005 \\
\hline Hierarchical level ( 1 = managerial $)$ & -.015 & -.042 & .011 & -.005 & -.014 & .066 & .072 & .044 \\
\hline Job function $(1=$ operational $)$ & .157 & -.008 & -.117 & -.058 & -.065 & -.076 & -.050 & -.040 \\
\hline Work interdependence & .024 & -.012 & -.031 & -.033 & -.027 & -.003 & .008 & .004 \\
\hline $\mathrm{H}_{1}$ : Tenacity & & $.595 * * *$ & $.472 * * *$ & $.421 * * *$ & $.404 * * *$ & $.378 * * *$ & $.394 * * *$ & $.386 * * *$ \\
\hline Goal congruence & & & -.075 & $-.105^{+}$ & -.073 & -.071 & -.063 & $-.097 *$ \\
\hline Trust & & & .063 & .080 & .075 & .025 & -.018 & -.011 \\
\hline Organizational support for change & & & $.282 * * *$ & $.279 * * *$ & $.258 * * *$ & $.235 * * *$ & $.188 * * *$ & $.208 * * *$ \\
\hline $\mathrm{H}_{2 \mathrm{a}}:$ Tenacity $\times$ Goal congruence & & & & $-.084 *$ & & & $.094 *$ & \\
\hline $\mathrm{H}_{2 \mathrm{~b}}:$ Tenacity $\times$ Trust & & & & & $-.137 * * *$ & & & .072 \\
\hline $\begin{array}{l}\mathrm{H}_{3}: \text { Tenacity } \times \text { Organizational support } \\
\text { for change }\end{array}$ & & & & & & $-.242 * * *$ & $-.188 * * *$ & $-.196 * * *$ \\
\hline $\begin{array}{l}\text { Organizational support for change } \times \\
\text { Goal congruence }\end{array}$ & & & & & & & -.033 & \\
\hline $\begin{array}{l}\text { Organizational support for change } \times \\
\text { Trust }\end{array}$ & & & & & & & & $-.071 *$ \\
\hline $\begin{array}{l}\mathrm{H}_{4 \mathrm{a}}: \text { Tenacity } \times \text { Organizational } \\
\text { support for change } \times \text { Goal } \\
\text { congruence }\end{array}$ & & & & & & & $.049 *$ & \\
\hline $\begin{array}{c}\mathrm{H}_{4 \mathrm{~b}}: \text { Tenacity } \times \text { Organizational } \\
\text { support for change } \times \text { Trust }\end{array}$ & & & & & & & & $.038^{+}$ \\
\hline $\mathrm{R}^{2}$ & .069 & .445 & .590 & .610 & .643 & .737 & .764 & .758 \\
\hline $\mathrm{R}^{2}$ change & & $.376 * * *$ & $.145 * * *$ & $.020 *$ & $.053 * * *$ & $.147 * * *$ & $.174 * * *$ & $.168 * * *$ \\
\hline
\end{tabular}

Notes: $\mathrm{N}=109$; unstandardized coefficients (two-tailed $p$-values).

${ }^{* *} p<.01 . * p<.05 .{ }^{+} p<.10$. 